\title{
APLIKASI REKAPITULASI DATA MAHASISWA SEKOLAH VOKASI IPB BERBASIS WEB
}

\author{
Risa Tri Caesarajmi \\ Program Studi Informatika, Fakultas Teknik dan Ilmu Komputer, Universitas Indraprasta PGRI \\ Jalan Raya Tengah No 80, Kelurahan Gedong, Pasar Rebo, Jakarta Timur \\ risainf48@gmail.com
}

\begin{abstract}
Abstrak
Penggunaan teknologi sangatlah luas, salah satu dari penggunaan teknologi adalah dalam bidang pendidikan. Tidak hanya guru, dosen, mahasiswa saja yang membutuhkan perkembangan teknologi, pegawai tenaga kependidikan juga membutuhkan penggunaan teknologi yang terbaru. Salah satu penggunaan teknologi yang dapat dipakai oleh pegawai tenaga kependidikan adalah rekapitulasi atau laporan. Tujuan dari penelitian ini adalah mempermudah pegawai dalam membuat laporan data mahasiswa. Rekapitulasi yang dilakukan berdasarkan jumlah mahasiswa berdasarkan kelas, tahun masuk, tingkat dan status. Metode yang dilakukan adalah metode prototype. Metode ini dimulai dengan mengumpulkan kebutuhan pelanggan terhadap perangkat lunak yang akan dibuat. Kemudian dibuatlah progam prototipe agar pelanggan lebih terbayang dengan apa yang diinginkan.pada tahap ini biasanya pengembang menyediakan tampilan dengan simulasi alur perangkat lunak sehingga tampak seperti perangkat lunak yang sudah jadi. Aplikasi rekapitulasi ini menghasilkan keluaran berupa hasil dari jumlah mahasiswa berdasarkan kelas, tingkat, tahun masuk dan status dalam bentuk pdf.
\end{abstract}

Kata Kunci: aplikasi, rekapitulasi, data, mahasiswa, data mahasiswa, laporan.

\section{Abstract}

The use of technology is very widespread, one of the uses of technology is in the field of education. Not only teachers, lecturers, students who need the development of technology, education personnel also need the use of the latest technology. One of the uses of technology that can be used by education personnel is recapitulation or report. The purpose of this research is to make it easier for employees to report student data. Recapitulation is done based on the number of students based on class, year of entry, level and status. The method performed is the prototype method. This method starts by collecting the customer's need for the software to be created. Then a prototype program is created so that customers are more imaginable with what they want.at this stage usually the developer provides a view with a software flow simulation so that it looks like the finished software. This recapitulation application generates output in the form of the result of the number of students based on class, level, year of entry and status in pdfform.

Keyword: application, recapitulasion, data, students, student data, report.

\section{PENDAHULUAN}

Sekolah vokasi IPB merupakan salah satu universitas yang bergerak di bidang pendidikan. Sistem pengolahan data yang terdapat pada Sekolah Vokasi IPB untuk keperluan rekapitulasi masih menggunakan sistem yang sederhana dan manual. Pengolahan data mahasiswa untuk rekapitulasi merupakan salah satu bentuk pelayanan administrasi dari universitas. Selama ini pengolahan data mahasiswa untuk rekapitulasi masih menggunaka microsoft excel, sehingga bila terjadi penambahan data setelah rekapitulasi selesai akan memakan waktu yang lama. Sistem pengolahan data mahasiswa sangat penting dalam membantu. Dengan adanya sistem ini diharapkan dapat memberi kemudahan kepada pengelola data untuk mendapatkan informasi yang terkait dengan data mahasiswa. Data dapat didefinisikan sebagai bahan keterangan tentang kejadian kejadian nyata atau fakta - fakta yang dirumuskan dalam sekelompok lambang tertentu yang tidak acak, yang menunjukkan jumlah, tindakan, atau hal. Data dapat berupa catatan - catatan dalam kertas, buku atau tersimpan sebagai file dalam basis data. Data menjadi bahan dalam suatu proses pengolahan data (Sutanta, 2011). 
Tujuan dari penelitian ini adalah untuk menghasilkan sebuah aplikasi rekapitulasi data dengan berbasis web yang dapat digunakan untuk memudahkan kinerja kerja, menghasilkan sebuah aplikasi yang dapat digunakan untuk merekapitulasi data mahasiswa aktif berdasarkan tingkat, kelas, tahun masuk dan status. Application program atau perangkat lunak aplikasi yaitu suatu perangkat lunak yang digunakan oleh pengguna komputer dalam melakukan tugas-tugas tertentu untuk mempermudah suatu pekerjaan. Istilah aplikasi muncul sekitar tahun 1993 di bidang teknologi informasi. Aplikasi biasa disingkat dengan sebutan App (Septiana, 2016). PHP (PHP Hypertext Preprocessor) merupakan bahasa pemrograman script server - side yang didesain untuk pengembangan web. Disebut bahasa pemrograman server side karena PHP diproses pada komputer server. Kemudahan dan kepopuleran PHP sudah menjadi standar bagi programer web diseluruh dunia (Madcoms, 2016).

Manfaat dari penelitian ini adalah dapat meningkatkan keefektifan dan kemudahan dalam melakukan pekerjaan yang berkaitan dengan data mahasiswa dan pihak Sekolah Vokasi mempunyai sistem berbasis web dalam penanganan data rekapitulasi data mahasiswa aktif.

\section{PENELITIAN RELEVAN}

Penelitian yang dilakukan oleh (Bahtiar, 2018) yang berjudul Perancangan Sistem Informasi Nilai Siswa SMK Perintis Depok Berbasis Web. Hasil penelitian ini adalah sistem pembelajaran dan nilai siswa yang ada di SMK PERINTIS 1 DEPOK sudah terkoperisasi baik pengolahan data, rekapitulasi dan penyimpanan data.

Penelitian yang dilakukan oleh (Wikandono, 2016) yang berjudul Perancangan Sistem Informasi Kehadiran Siswa SMA Pelita Depok Berbasis Web PHP. Hasil penelitian ini adalah Sistem Informasi Kehadiran Siswa ini dapat membantu dalam pembuatan laporan-laporan rekapitulasi data kehadiran siswa, laporan perkelas dan persemester sehingga menghasilkan laporan yang akurat.

Penelitian yang dilakukan oleh (Widiartha\&Aristana, 2018) yang berjudul Sistem Informasi Pengelolaan Nilai Mahasiswa Berbasis Web Pada STMIK STIKOM Indonesia, hasil peneltian dari sistem yang dibangunnya adalah Dalam sistem yang dibangun menyediakan fitur seperti pengaturan sistem, setting pengelolaan nilai, export templete form penilaian, import file excel penilaian secara otomatis dosen maupun staff dapat mencetak laporan yang dibutuhkan terkait rekapitulasi nilai mahasiswa

\section{METODE PENELITIAN}

Model prototipe dimulai dengan mengumpulkan kebutuhan pelanggan terhadap perangkat lunak yang akan dibuat. Kemudian dibuatlah progam prototipe agar pelanggan lebih terbayang dengan apa yang diinginkan.pada tahap ini biasanya pengembang menyediakan tampilan dengan simulasi alur perangkat lunak sehingga tampak seperti perangkat lunak yang sudah jadi. Pelanggan akan mengevaluasi samapi ditemukan spesifikasi yang sesuai dengan keinginan.

Berikut ini adalah gambar dari model prototipe.

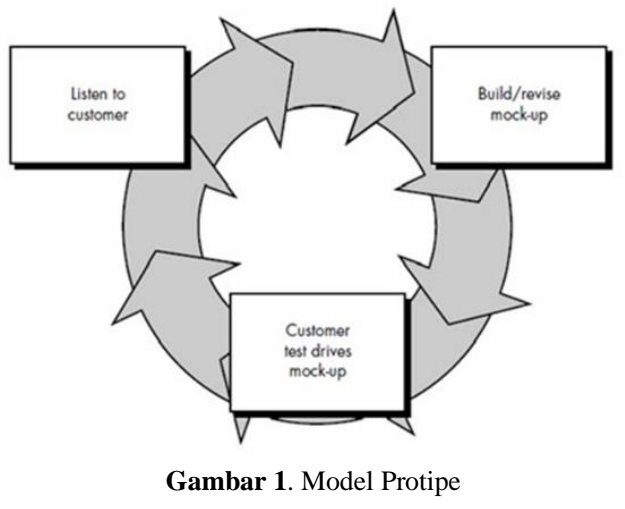


Mock-up adalah sebuah media visual atau sebuah gambaran dari konsep-konsep dasar yang dikumpulkan. Sebuah mock-up disebut sebagai prototipe perangkat lunak jika menyediakan atau dapat mendemonstrasikan sebagian besar fungsi sistem perangkat lunak. Perulangan terjadi pada pembuatan prototipe sampai sesuai dengan keinginan pelanggan.

\section{HASIL DAN PEMBAHASAN}

Dari tahapan penelitian yang dilakukan, hasil dari sebuah perancangan yang merupakan hasil dari pengimplementasian perancangan ke dalam system yang dibangun. Berikut hasil dari penelitian:

Dalam merancang aplikasi rekapitulasi data mahasiswa menggunakan data flow diagram untuk menggambarkan proses yang akan berjalan. Berikut merupakan diagram konteks dari system yang dibangun.

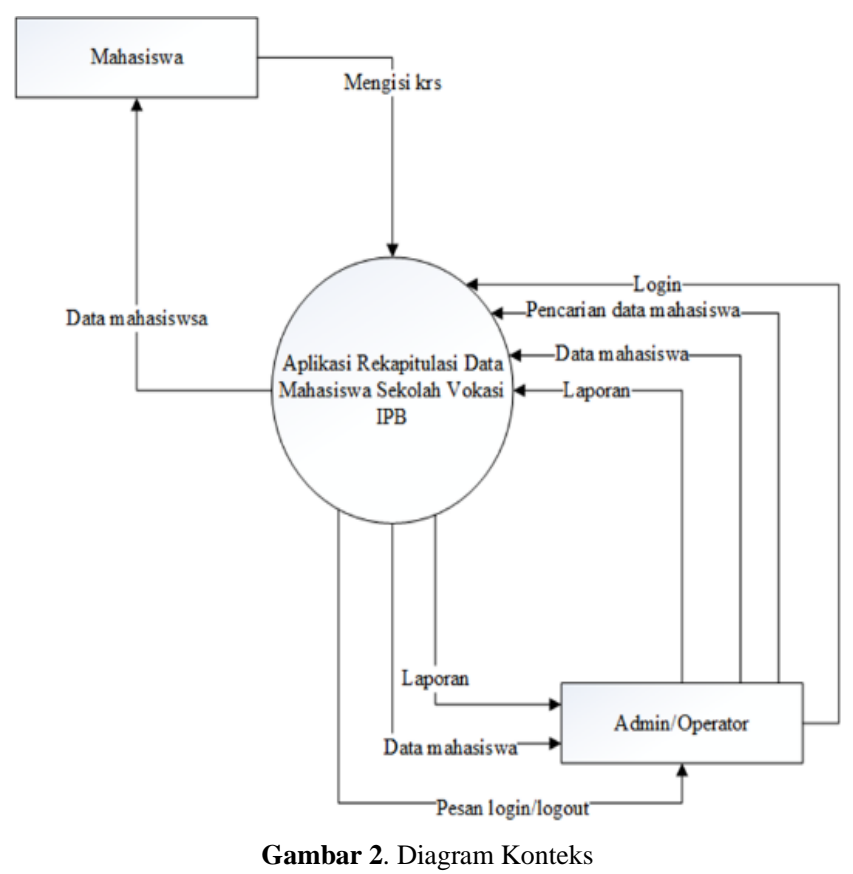

Erd merupakan model yang menjelaskan hubungan antar data dalam basis data yang mempunyai relasi.

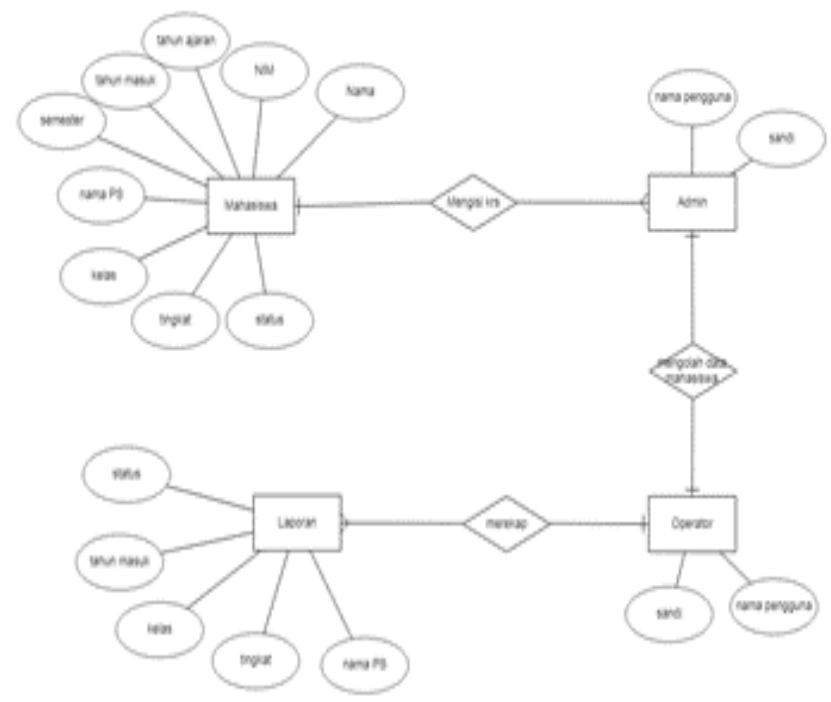

Gambar 3. Entity Relationship Diagram 


\section{Tampilan Layar}

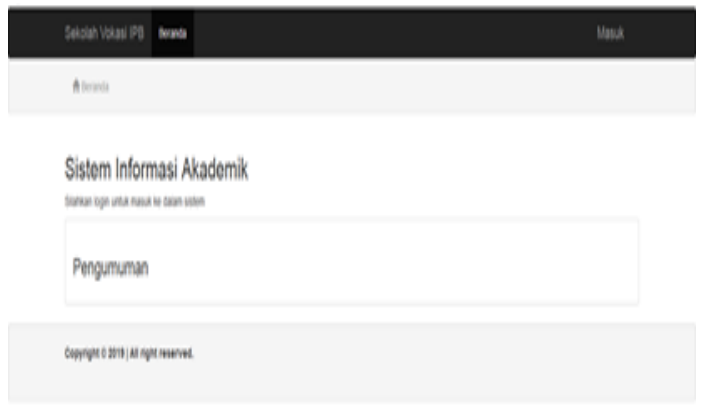

Gambar 4. Tampilan Layar Beranda

Tampilan layar beranda ini muncul diawal saat pengoperasian program aplikasi rekapitulasi data mahasiswa. Pada tampilan ini hanya berisikan pengumuman akademik.

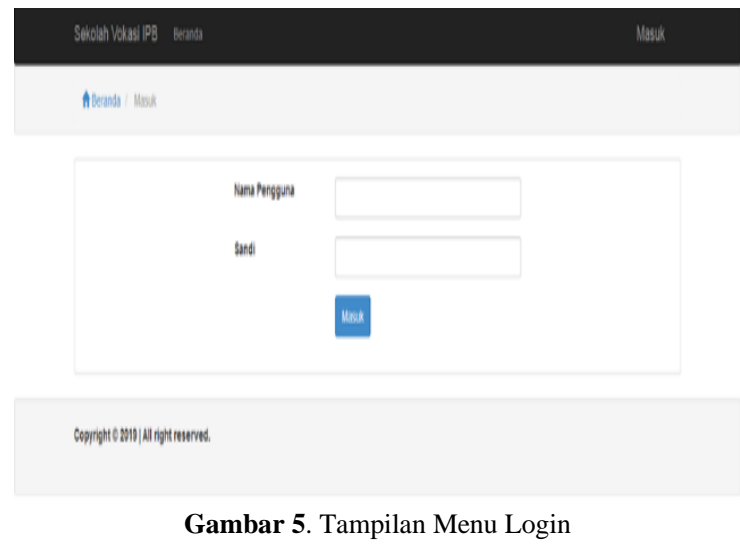

Tampilan login ini muncul setelah memilih menu masuk. Pada tampilan ini pengguna diminta mengisi nama pengguna dan sandi yang sesuai dengan hak akses. Bila pengguna tersebut adalah admin maka menunya bisa diakses semua tetapi bila pengguna tersebut adalah operator menu yang bisa diakses adalah data mahasiswa dan rekapitulasi.

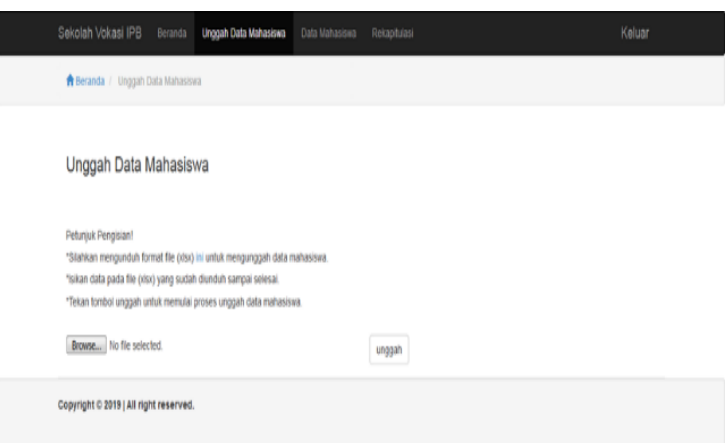

Gambar 6. Tampilan Unggah Mahasiswa

Menu unggah data mahasiswa hanya bisa diakses oleh admin. Pada menu ini menampilkan data mahasiswa yang harus diunggah. Format data excel yang diperlukan dapat diunduh juga dengan memilih kata 'ini' yang berwarna biru. Setelah data mahasiswa diisi sesuai format maka admin menggunggah data mahasiswa. 


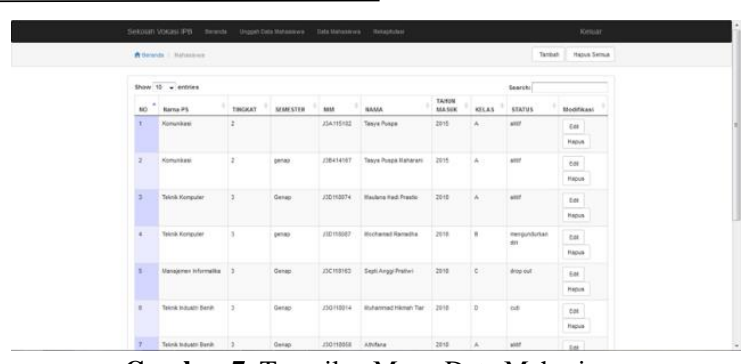

Gambar 7. Tampilan Menu Data Mahasiswa

Menu data mahasiswa ini menampilkan data mahasiswa aktif yang telah diunggah oleh admin. Pada menu ini operator dapat menambahkan data mahasiswa, mengubah dan menghapus data mahasiswa. Menu ini dapat diakses oleh admin dan operator.

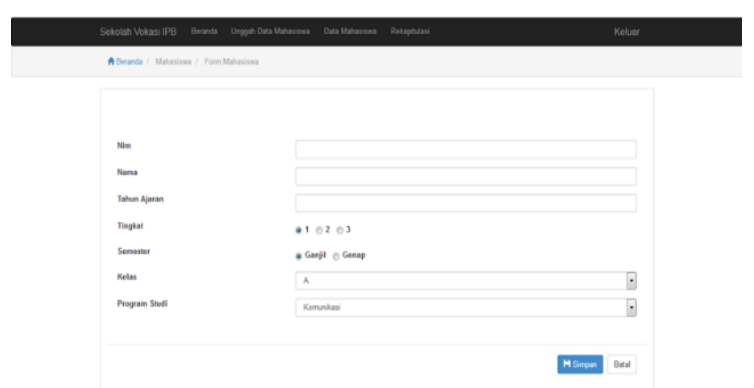

Gambar 8. Tampilan Tambah Data Mahasiswa

Tampilan tambah data mahasiswa ini berfungsi untuk menambahkan data mahasiswa ke dalam sistem aplikasi data mahasiswa operator akan mengisikan data NIM, nama, tahun ajaran, tingkat, semester, kelas, program studi, tahun masuk, dan status. Setelah mengisikan data maka operator menekan tombol simpan untuk menyimpan data mahasiswa tersebut.

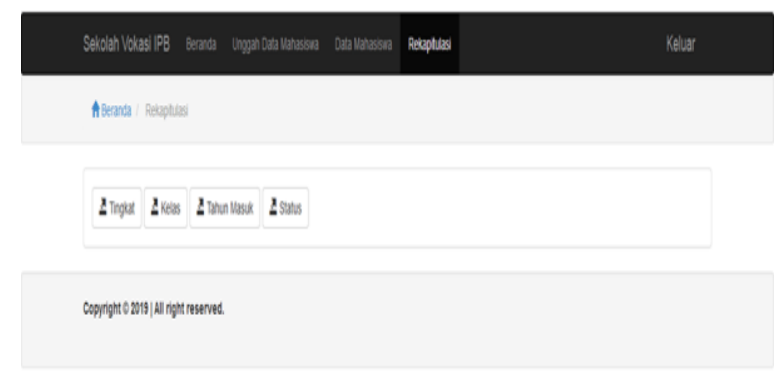

Gambar 9. Tampilan Menu Rekapitulasi data

Pada tampilan rekapitulasi ini operator memilih data yang direkap. Data yang dibuat laporannya pada aplikasi ini ada dua yaitu rekapitulasi berdasarkan tingkat mahasiswa, rekapitulasi berdasarkan kelas, rekapitulasi berdasarkan tahun masuk dan rekapitulasi berdasarkan status mahasiswa. 


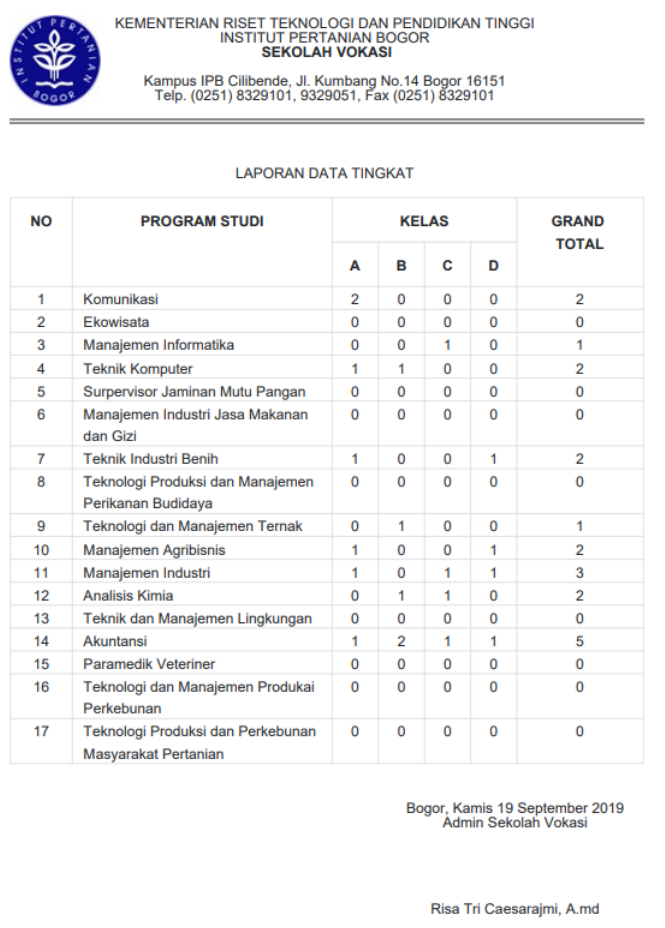

Gambar 10. Laporan Data Mahasiswa Berdasarkan Tingkat

Laporan Data Mahasiswa Berdasarkan Tingkat berisikan program studi, tingkat, kelas, tahun masuk, status dan total. Data laporan ini berupa pdf.

\section{SIMPULAN}

Aplikasi rekapitulasi data mahasiswa dapat memperpudah pengolahan data mahasiswa sekolah Vokasi IPB. Dalam perancangan ini data mahasiswa disimpan di database sehingga mempercepat pengolahan data mahasiswa. Aplikasi rekapitulasi data mahasiswa ini dapat membantu dalam pembuatan laporan-laporan rekapitulasi data mahasiswa berdasarkan tingkat, berdasarkan kelas persemester, berdasarkan tahun masuk, dan berdasarkan status sehingga menghasilkan data yang akurat.

\section{DAFTAR PUSTAKA}

Bahtiar, Y. (2018). Perancangan Sistem Informasi Nilai Siswa SMK Perintis 1 Depok Berbasis Web. MADCOMS. (2016). PEMROGRAMAN PHP dan MySQL untuk pemula. In Andi.

Septiana, L. (2016). Perancangan Sistem Pakar Diagnosa Penyakit Ispa Dengan Metode Certainty Factor Berbasis Android. Jurnal Techno Nusa Mandiri, 13(2), 1-7. https://doi.org/10.33480/techno.v13i2.200

Sutanta, E. (2011). Basis Data Dalam Tinjauan Konseptual. ANDI.

Widiartha, K. K., \& Aristana, M. D. W. (2018). Sistem Informasi Pengelolaan Nilai Mahasiswa Berbasis Web Pada Stmik Stikom Indonesia. Joutica, 3(1), 109. https://doi.org/10.30736/jti.v3i1.197

Wikandono, A. (2016). Perancangan Sistem Informasi Kehadiran Siswa SMA PELITA Depok Berbasis Web PHP. 